\title{
The peculiarities of fatigue failure for pipe steels of different strength classes (pipes with welds)
}

\author{
V. N. Kuskov, I. M. Kovenskiy \& K. V. Kuskov \\ Tyumen State Oil and Gas University, Russia
}

\begin{abstract}
Variable loads, as compared with static loads, have a greater impact on the condition of pipelines. They lead to the degradation of metal and significantly reduce the service life of pipelines. This paper considers the mechanism of fatigue crack development in steels of different strength classes (K50, K60 and K62), which helps to specify the fracture mechanism and evaluate the residual life of a pipeline material.

Fatigue tests were carried out until the complete failure of specimens at a maximum tensile load below the yield strength of the steels. The number of cycles to failure of specimens with no visible weld defects was reduced by more than $40 \%$, as compared with seamless specimens. If there were allowable defects of up to $0.4 \mathrm{~mm}$ in size, then the number of cycles was reduced by 5-12 times. Photographs of the fractures are provided.

The tests allowed the authors to establish the peculiarities of K60 steel failure and to calculate regression equations of the second order between the number of cycles to failure of the specimen, the maximum tensile stress and the stress range during fatigue tests. An essential effect of the stress range (in the range of $18-44 \mathrm{MPa})$ on the number of cycles to failure of the specimen has been established. After its reduction to $6-8 \%$ of the maximum tensile stress, the stress range ceases to affect the number of cycles. Since the appearance of the first visually perceptible cracks, the specimens endured from 4,000 to 10,000 cycles to failure. This makes it possible to detect the initiation of a failure and take steps to repair the defective part.

Knowing the number of pressure fluctuations in the pipeline, which are registered in the control room, one can use the equations to predict the residual life of a particular section of the pipeline.

Keywords: pipeline steel, fatigue cracks, welds, regression equations.
\end{abstract}




\section{Introduction}

To date, the problem of strain aging of pipe steels with a ferrite-pearlite structure, of strength classes up to K50 has been studied in sufficient detail. However, in national and international practices of pipeline construction there is a tendency of applying high strength (K60, K65 and higher) steels. Ilukhin [1], analyzing changes in the complex of mechanical properties during strain aging of pipe steels, showed that microalloyed steel of K65 strength class(with a predominantly bainitic structure) has a less tendency to strain aging as compared to conventional low-alloy K55 steel (with a ferrite-pearlite structure). This is due to higher strength properties, alongside with the preservation of high ductility and critical brittle temperature up to a temperature of $60^{\circ} \mathrm{C}$. At the same time, the work of crack initiation differs insignificantly, whereas the work of crack propagation is significantly reduced, which should be taken into consideration when assessing the actual state of pipeline metal.

\section{Materials and technique of research}

For this study, we chose low-alloy steels of strength classes K50, K60 and K62 with different main types of hardening: solid solution hardening, pearlitic, grainboundary and dispersion hardening. Fatigue tests were performed at a ЦД-20 test machine with a $\Pi y 10$ pulsator, at a frequency of $10 \mathrm{~Hz}$ at $23 \pm 2{ }^{\circ} \mathrm{C}$. A variable tensile load from the maximum stress $\sigma_{\max }$ to the minimum stress $\sigma_{\min }$ acted along the axis of the specimen, perpendicular to the weld seam. Maximum loads were $80 \%$ and $60 \%$ of the yield strength of steel and the stress range A $\sigma$ was from 16 to $46 \mathrm{MPa}$.

The microstructure of the specimens was studied using a MЕТАМ ЛВ-31 light microscope and a JSM-6510 scanning electron microscope at magnifications from 30 to 5000 times. Impact strength was determined using a MK-30A pendulum impact testing machine, on specimens with a U-shaped notch.

\section{Results and discussion}

On the basis of the results of fatigue tests [2, 3], using the program STATISTICA 6.1 (multiple correlation coefficient 0.95 , level of significance 0.01 ) we calculated regression equations between the number of cycles to failure of specimen $\mathrm{N}$ and test parameters: the maximum tensile stress $\sigma \mathrm{max}$ and the stress range $A \sigma$.

For welded specimens of strength class K50 steel

$$
\begin{gathered}
\mathrm{N}=1,5768 \cdot 10^{6}+743,344 \cdot \sigma_{\max }-82834,5135 \cdot \mathrm{A}_{\sigma}-3,0898 \cdot \sigma^{2}{ }_{\max }+ \\
+58,6958+\mathrm{A}_{\sigma} \cdot \sigma_{\max }+1031,6689 \cdot \mathrm{A}_{\sigma}^{2}
\end{gathered}
$$


For strength class K60 steel

$$
\begin{gathered}
\mathrm{N}=5,1787 \cdot 10^{5}+251,4986 \cdot \sigma_{\max }+151,026 \cdot \mathrm{A}_{\sigma}-0,6914 \cdot \sigma_{\max }^{2}- \\
-2,1285 \cdot \mathrm{A}_{\sigma} \cdot \sigma_{\max }-164,4628 \cdot \mathrm{A}_{\sigma}{ }^{2} ;
\end{gathered}
$$

For strength class K62

$$
\begin{gathered}
\mathrm{N}=1,5428 \cdot 10^{6}-3370,1296 \cdot \sigma_{\max }-21406, \quad \cdot \mathrm{A}_{\sigma}+7,1868 \cdot \sigma_{\max }^{2}- \\
-77,2361 \cdot \mathrm{A}_{\sigma} \cdot \sigma_{\max }+526,6146 \cdot \mathrm{A}_{\sigma}^{2} .
\end{gathered}
$$

Figure 1 shows an example of a geometric interpretation of resulting equations, which indicates a complex correlation of the investigated parameters.

Fractographs of fracture surfaces at different magnifications are shown in Figure 2. Fracture pits of different sizes are visible, which merge into one large pit consisting of a dozen smaller ones. Inside the pits, globular formations were found, which could become the nuclei of crack initiation.

Delamination of fracture surfaces, which appeared after fatigue tests, has been found in both welded and seamless specimens of class K60 steel. Fracture surfaces of other steels had small secondary cracks, 30-150 microns long.

Table 1 shows the results of impact tests of specimens subjected to cyclic impact test for half the average number of cycles to failure of the specimens.

The obtained results indicate a decrease in impact strength of specimens after fatigue tests. The magnitude of $\mathrm{KCU}$ is about $35 \%$ of the impact strength of initial specimens at high maximum tensile stresses, and $80-87 \%$ at low stresses.

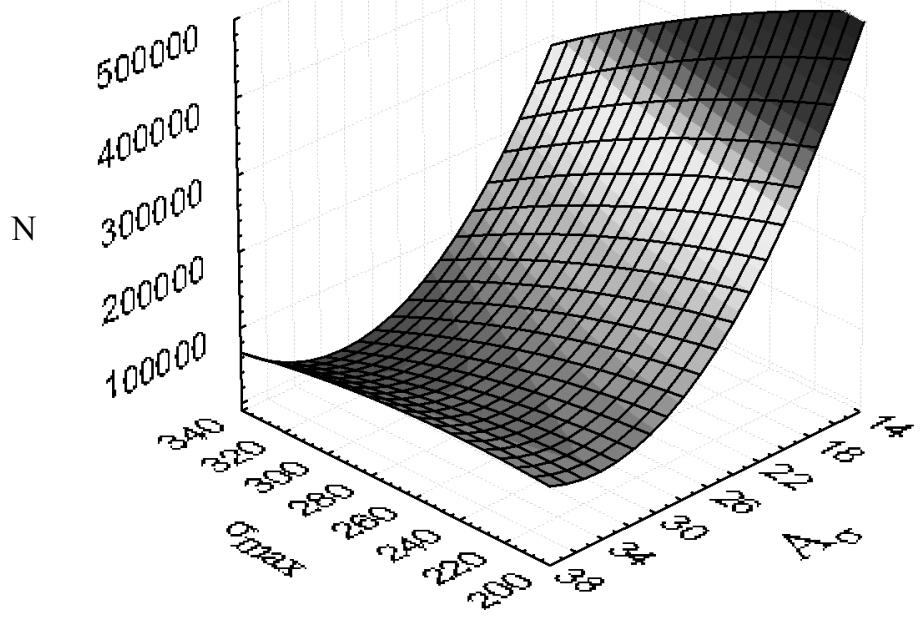

Figure 1: Graphical interpretation of the equation of correlation between the number of cycles to failure of welded class K50 steel specimens N, maximum tensile stress $\sigma$ max and stress range A $\sigma$. 


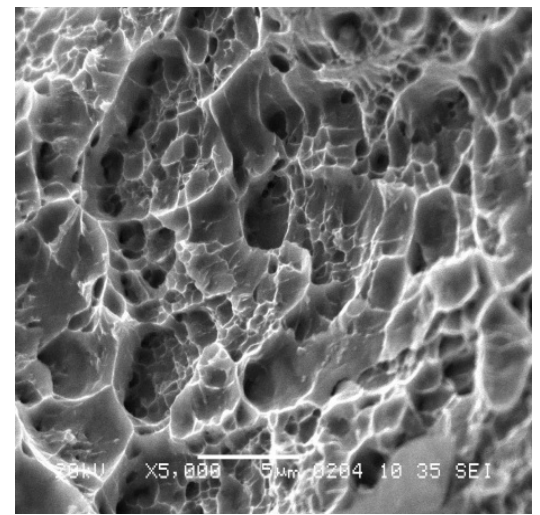

a

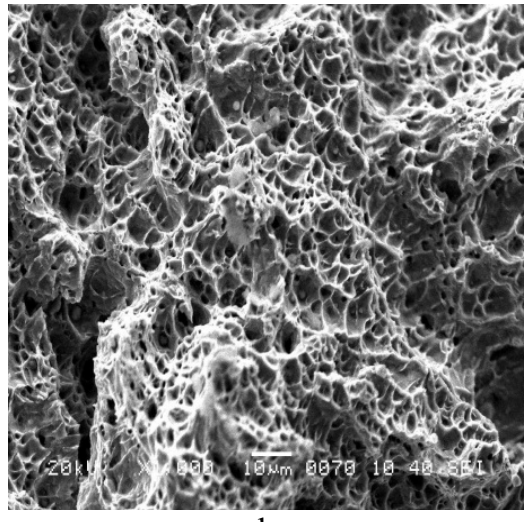

b

Figure 2: Examples of fractographs of fracture surfaces of steels: a-strength class K50 (x5000), b-strength class K60 (x 1000).

Table 1: Effect of cyclic test parameters on impact strength.

\begin{tabular}{|c|c|c|c|c|}
\hline $\begin{array}{c}\text { Strength } \\
\text { class } \begin{array}{l}\text { Steel } \\
\text { stef }\end{array}\end{array}$ & $\begin{array}{c}\text { Maximum } \\
\text { tensile stress } \\
\sigma_{\max }, \mathrm{MPa},\end{array}$ & $\begin{array}{c}\text { Stress range } \\
\mathrm{A}_{\sigma}, \mathrm{M} \Pi \mathrm{a}\end{array}$ & $\begin{array}{c}\text { Number of } \\
\text { loading } \\
\text { cycles }\end{array}$ & $\begin{array}{c}\text { Impact } \\
\text { strength } \\
\mathrm{KCU}, \mathrm{J} / \mathrm{cm}^{2}\end{array}$ \\
\hline \multirow{3}{*}{$\mathrm{K} 50$} & 330 & 18 & 62500 & 7,9 \\
\cline { 2 - 5 } & 250 & 18 & 216600 & 18,7 \\
\cline { 2 - 5 } & 0 & 0 & 0 & 21,6 \\
\cline { 2 - 5 } K60 & 393 & 22 & 208200 & 10,3 \\
\cline { 2 - 5 } & 297 & 22 & 221000 & 23,8 \\
\cline { 2 - 5 } & 0 & 0 & 0 & 29,7 \\
\hline
\end{tabular}

The obtained results of fatigue tests and structural studies have allowed to develop an algorithm, shown schematically in Figure 3, and a technique for evaluation of the residual life of continuous duty constructions, using diagrams of the type $\mathrm{N}=\mathrm{f}\left(\sigma_{\max }, \mathrm{A}_{\sigma}\right)$ and taking into account confidence intervals.

\section{Conclusions}

1. It has been found that the presence of weld reduces the amount of load cycles to failure of K50 steel by 1.5-12 times, depending on test conditions and imperfection of the weld, K62 steel by 1.5-2.0 times and K60 steel by 1.15-1.8 times, as compared with seamless specimens. Fatigue resistance significantly depends on the size and shape of allowable defects, which are stress concentrators. 


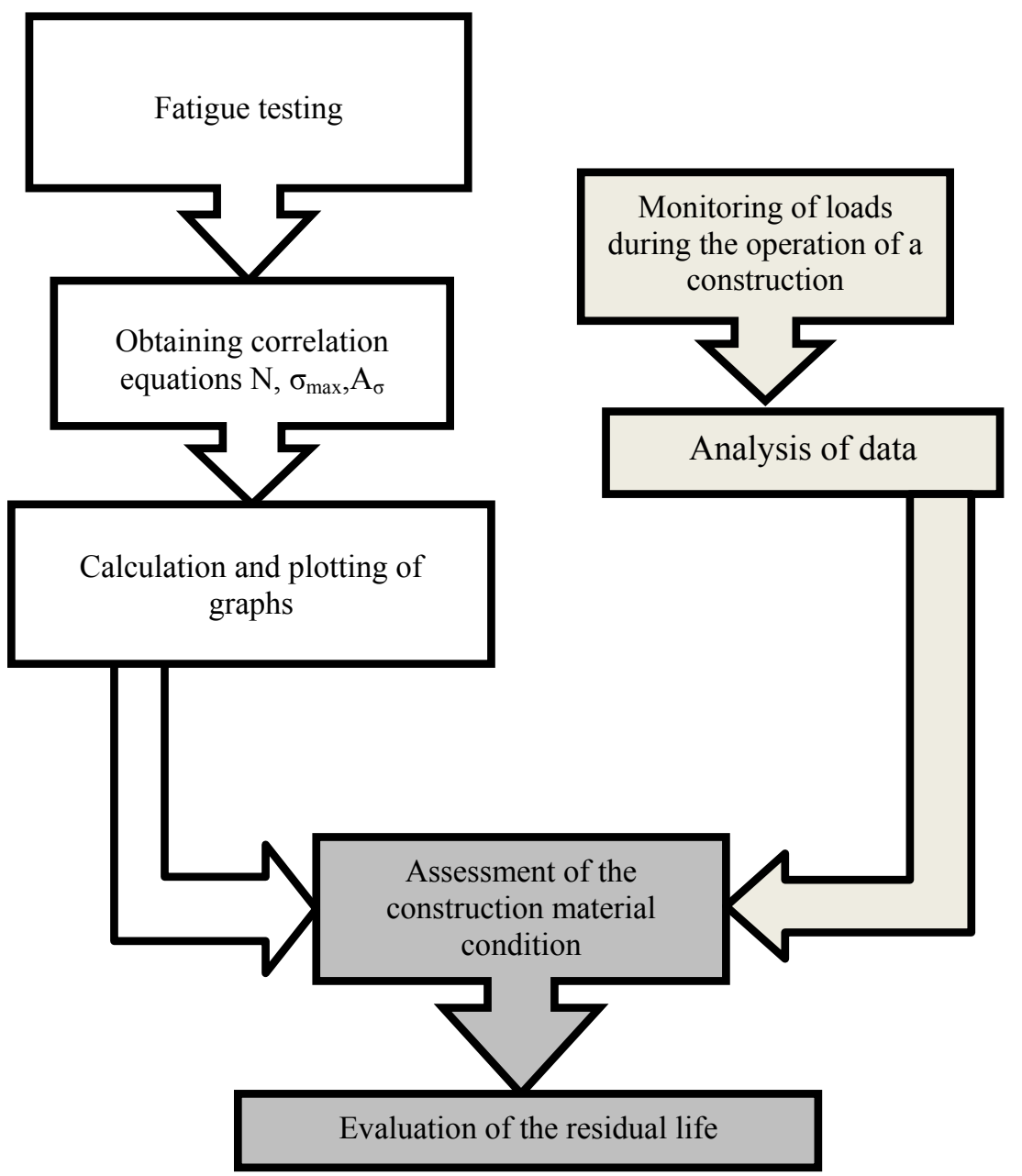

Figure 3: Algorithm of the technique for evaluation of the residual life of a construction.

2. The number of cycles to failure of the investigated steels since the appearance of first cracks has been determined. The obtained data allow timely detection of incipient fractures and elimination of the defective portion.

3. Quadratic equations have been obtained which describe the correlation between the number of cycles to failure of welds in the investigated steels, the maximum tensile stress and the stress range. These equations allow estimating the residual life of a welded construction with regard to designated test parameters. 
894 Energy Production and Management in the 21st Century, Vol. 2

\section{References}

[1] Ilukhin, V.Y., Investigation of the effect of strain aging on the corrosion resistance and susceptibility to hydrogen embrittlement of pipe steels of different strength category, Moscow, 155, 2009.

[2] Kuskov, K.V., Kovenskiy, I.M., Kuskov, V.N., Obukhov, A.G., Fatigue testing of welded joints of pipe steel $09 \Gamma 2 \mathrm{C}$. Proceedings of higher educational institutions. Oil and Gas, 3, pp 80-82, 2012.

[3] Kovenskiy, I.M., Kuskov, K.V., Venediktova, I.A., Fatigue failure of welded joints of pipe steels 09Г2C and $17 \Gamma 1 \mathrm{C}-\mathrm{Y}$. Omsk Research Bulletin, 2, pp 51-53, 2013. 